\title{
Influence of Iron Deficiency on Olfactory Behavior in Weanling Rats
}

\author{
V. M. Ruvin Kumara ${ }^{1,2}$, Marianne Wessling-Resnick ${ }^{1^{*}}$ \\ ${ }^{1}$ Department of Genetics and Complex Diseases, Harvard School of Public Health, Boston, USA \\ ${ }^{2}$ Department of Biochemistry, Faculty of Medicine, University of Ruhuna, Galle, Sri Lanka \\ Email: ruvin@vidanamadura.net, wessling@hsph.harvard.edu
}

Received February 2, 2012; revised March 3, 2012; accepted March 20, 2012

\begin{abstract}
Chronically high occupational exposure to airborne metals like iron can impair olfactory function, but little is known about how low iron status modifies olfactory behavior. To investigate the influence of body iron status, weanling rats were fed a diet with low iron content (4 - $7 \mathrm{ppm})$ to induce iron deficiency anemia and olfactory behavior was compared to control rats fed an isocaloric diet sufficient in iron (210 - $220 \mathrm{ppm})$. Iron-deficient rats had prolonged exploratory time for attractive odorants in behavioral olfactory habituation/dis-habituation tests, olfactory preference tests and olfactory sensitivity tests compared with control rats. No significant differences were observed for aversive odorants between the two groups. These findings suggest that iron-dependent functions may be involved in controlling and processing of olfactory signal transduction via self and lateral inhibition such that odorant signal remains stronger for longer times prolonging exploratory activity on attractive odorants in the behavioral tests. These findings establish that iron deficiency can modify olfactory behavior.
\end{abstract}

Keywords: Iron Deficiency; Olfactory Habituation/Dis-Habituation; Olfactory Sensitivity; Olfactory Signal Transduction

\section{Introduction}

Olfactory function is significantly impaired in metal workers and other individuals subjected to chronic occupational exposure to metals compared with the general population. For example, professional welders who work in enclosed spaces with poor ventilation exhibit significant olfactory dysfunction, typical of that observed in idiopathic Parkinson's disease [1,2]. Olfactory impairments have been reported in a number of neurodegenerative diseases in addition to Parkinson's disease, including Alzheimer's disease, and olfactory deficits suggest an early stage marker for Parkinson's and Alzheimer's disease [3-12]. Both disorders are associated with excessive iron deposition in the central nervous system [13-17]. While we have limited understanding about the association of neurodegenerative diseases with high brain iron and the impact on olfaction, how iron deficiency might influence the sense of smell has not been adequately addressed. The present study was designed to explore the relationship between low iron status of the body and behavioral olfactory functions, using a model of diet-induced iron deficiency anemia in weanling rats.

*Corresponding author.
It has been established that several iron-dependent enzymatic functions are necessary for proper olfaction. For example, neuronal nitric oxide synthase (nNOS), tryptophan dioxygenase (TDO), indoleamine 2,3-dioxygenase (IDO), 3-hydroxyanthranilic acid oxygenase (3-HAO) and tyrosine hydroxylase (TH) are necessary for olfactory signal transduction and all of these proteins require either heme or inorganic iron for structure and activity. Therefore, we designed the present study to investigate the relationship between behavioral olfactory functions and iron deficiency anemia. Behavioral olfactory functions in animals are initiated by involuntary inhalation followed by voluntary odorant sampling, or sniffing behavior, which plays an important role in odor information processing [18-22]. Simple habituation/dis-habituation tests can assess a rodent's ability to sense and differentiate between odors [23]. Using this approach, we determined that iron-deficient rats have prolonged exploratory time for attractive odorants, but not aversive odorants, compared to iron-sufficient controls. A mechanistic model is proposed based on these findings that explains how iron-dependent functions may be involved in controlling and processing of olfactory signal transduction via self and lateral inhibition such that exploratory activity is prolonged. 


\section{Materials and Methods}

\subsection{Animals, Diet and Odorants}

Animal protocols were approved by the Harvard Medical Area Animal Care and Use Committee. Three week-old Sprague-Dawley rats (Taconic Farms, Inc., Germantown, NY) were housed with 12 hour light-dark cycle. The control group was fed on standard chow containing 210 - 220 ppm iron (PicoLab 5053; PharmaServ) and the test group was fed an isocaloric iron-deficient diet containing 4 - 7 ppm iron (TD 99397, Harlan Teklad; Table 1) to induce iron deficiency anemia. Vanillin crystals (200 mg per vial per cage; Sigma-Aldrich) were used for background odor enrichment to habituate all rats. Attractive odorants eugenol (Sigma-Aldrich) and peanut butter (Shaw's Super Market Brand), and aversive odorants cinnamon oil (Sigma-Aldrich) and 2-methylbutyric acid (Sigma-Aldrich) were dissolved in a minimum volume of mineral oil to obtain the required concentration with the least possible contamination.

\subsection{Determination of Iron Status}

All rats were humanely killed after behavioral olfactory function tests, and blood, olfactory bulb, whole brain and liver were collected and weighed. Hematocrits and tissue non-heme iron concentrations were measured as previously described [24]. Iron concentrations in acid-hydrolyzed olfactory bulbs and whole brains were measured using Inductively-Coupled Plasma Optical Emission Spectroscopy (ICP-OES). Iron content was determined from emission readings at the Fe $238.204 \mathrm{~nm}$ emission line using an ICP-OES spectrometer (Optima DV 2000, PerkinElmer). The instrument was calibrated with dilutions of an iron standard spiked with yttrium internal standard (1 $\mathrm{mg} / \mathrm{L}$ ). Raw ICP results were calculated using WinLab 32 for ICP software (Perkin Elmer) to back-calculate the amount of iron in original tissue and are expressed as $\mu \mathrm{g}$ per gram of tissue.

\subsection{Behavioral Olfactory Functional Tests}

In the second week on their respective diets, rats in both groups were habituated for experimental handling and odorant vanillin for 5 - 7 days. A vial containing $200 \mathrm{mg}$

Table 1. Comparison of diet composition.

\begin{tabular}{ccccc}
\hline $\begin{array}{c}\text { Diet } \\
\text { Components }\end{array}$ & $\begin{array}{c}\text { Control Diet } \\
\text { (Picolab 5053) }\end{array}$ & \% Kcal & $\begin{array}{c}\text { Low Iron Diet } \\
\text { (TD 99397) }\end{array}$ & \% Kcal \\
\hline Iron, mg/kg & $210-220$ & & $4-7$ & \\
Protein, \% & 20.0 & $23.55 \%$ & 17.7 & $17.8 \%$ \\
Carbohydrate, \% & 68.7 & $64.52 \%$ & 69.8 & $70.4 \%$ \\
Fat, \% & 5.4 & $11.92 \%$ & 5.2 & $11.8 \%$ \\
Energy, kcal/g & 4.0 & & 4.0 & \\
\hline
\end{tabular}

of pure vanillin crystals was hung in each cage for background odor enrichment and a sham test of each of the following experiments without test odorant was performed with all rats to familiarize experimental handling and minimize disturbance to sniffing behavior.

\subsubsection{Behavioral Olfactory \\ Habituation/Dis-Habituation Test}

On the experimental day (post-natal day 42), each rat was habituated for 15 min with the vanillin cassette and a filter paper cassette attached to the clean cage without bedding. The rat was then transferred to a second cage (exactly as the first cage) and habituated for $5 \mathrm{~min}$. The test was performed in a third cage containing a test cassette with filter paper soaked with $50 \mu \mathrm{l}$ of $5 \%$ eugenol and a blank cassette with filter paper alone. Exploratory time for exactly 180 seconds was recorded using custom behavioral recording software (see below) while observing real time movement using the computer monitor. The rat was then transferred back to second cage again for dis-habituation for $5 \mathrm{~min}$. Successive tests sessions were performed five times with $5 \%$ eugenol in the test cage and the exploratory time calculated in each session was added to the total exploratory time of all five trials. In a final test, the rat was exposed once to $5 \%$ cinnamon oil instead of eugenol, and the test was repeated for dis-habituation and discrimination as described above. Exploratory time was calculated in milliseconds using Sony Vegas Pro10 by navigating video frame by frame back and forth and then compared with the control group.

\subsubsection{Behavioral Olfactory Preference Test}

All the habituation processes were performed as described for the olfactory habituation/dis-habituation test. The test was performed in the test cage containing test cassette with water and a blank cassette. Exploratory time for 180 seconds was recorded and then the rat was transferred to second cage for dis-habituation (5 min). The procedure was repeated once with $7.5 \%$ peanut butter, and once with 7.5\% 2-methylbutyric acid, and total exploratory time was measured.

\subsubsection{Behavioral Olfactory Sensitivity Test with Eugenol and Peanut Butter}

All the habituation processes were accomplished using two separate cages as explained in olfactory habituation/dis-habituation test. Rats were exposed to eugenol for the first time in their life and only once for each concentration. The test was performed in the test cage containing test cassette with $0.9 \%$ eugenol and a blank cassette and exploratory time was recorded for 180 seconds and the rat was transferred to second cage for dis-habituation (5 min). The procedure was repeated $1.8 \%$ and $3.6 \%$ eugenol. The test procedures were also repeated ex- 
cept that $2.5 \%$, 5\% and $10 \%$ peanut butter was employed as odorant.

\subsection{Behavioral Recording and Analyzing Software}

Real time behavioral recording software was developed to monitor and record digital video from a Sony SSCDC374 high resolution color CCD surveillance video camera to a hard drive while monitoring their real time behavior on computer screen. The software was synchronized with computer clock, automated to record exploratory time within given time period, measured recording time in milliseconds and number of frames per given time (180 seconds). The software was pre-tested and compared with Sony Vegas Pro10 \& Roxio creator 2011 for accuracy. Sony Vegas Pro10 was used to analyze the recorded video and measure total exploratory time within $180 \mathrm{sec}-$ onds. Time line of the video was navigated back and forth frame by frame to find out the starting and ending time points of sniffing. Sniffing starting time was subtracted from sniffing ending time and number of frames was converted into milliseconds to calculate exploratory time. The rats sniffed the odorant cassette several times within a 180 second period. Total exploratory time within 180 seconds was calculated by adding fractions of sniffing durations.

\subsection{Statistical Analysis}

Data were expressed as mean \pm SEM. Data was analyzed by one-way ANOVA using IBM SPSS version 19 statistical software and differences were considered significant at $\mathrm{P}<0.05$.

\section{Results}

\subsection{Characteristics of Iron-Deficient and Control Rats}

After 3 weeks on a low-iron diet and at the beginning of behavioral tests, hematocrit and body weights were significantly reduced in iron-deficient anemic rats compared to rats fed the control iron-sufficient diet (Table 2). Serum iron and liver non-heme iron levels were also signifycantly lowered in iron-deficient rats compared with controls. ICP-OES analysis also confirmed the significant reduction of the iron levels in olfactory bulbs $(\mathrm{P}<0.001$, $\mathrm{n}=8)$ and whole brains $(\mathrm{P}<0.001, \mathrm{n}=10)$ of anemic rats compared with respective values of control rats (Figure 1).

\subsection{Olfactory Habituation/Dis-Habituation Test}

Total exploratory time for 5\% eugenol was significantly prolonged in iron-deficient rats compared with control rats (Figure 2(a)). In contrast, rats were completely dis- habituated for an aversive odorant, cinnamon oil, and there was no significant difference between groups. Total exploratory time in individual trial sessions of 180 seconds was significantly prolonged in the 1st trial $(\mathrm{P}<$ $0.001, \mathrm{n}=16)$ and in the $2^{\text {nd }}, 3^{\text {rd }}, 4^{\text {th }}$ and $5^{\text {th }}$ trials $(\mathrm{P}<0.05$, $\mathrm{n}=16$ ) comparing iron-deficient rats with control rats (Figure 2(b)). There was a significant decline in exploratory time from 1st to 4th session in iron-deficient rats representing gradual increase in odor discrimination and adaptation. There was a significant decline in total exploratory time for $5 \%$ eugenol in $1^{\text {st }}$ and $2^{\text {nd }}$ sessions $(\mathrm{P}<0.05$, $\mathrm{n}=16$ ) in control rats. Both iron-deficient and control rats dis-habituated when exposed to aversive odorant cinnamon oil in the 6th session (40 min after starting the experiment; Figure 2(a)). There was no significant difference in total exploratory time for 5\% cinnamon oil within the $180 \mathrm{sec}$ test period; both groups recognized cinnamon oil quickly and moved away from the odor.

Table 2. Physiological characteristics of iron-deficient and control rats.

\begin{tabular}{ccccc}
\hline & Anemic rats & n & Control rats & n \\
\hline Body weight, g & ${ }^{*} 209.12 \pm 8.651$ & 16 & $283 \pm 7.622$ & 16 \\
Liver, \% Body weight & ${ }^{*} 4.17 \pm 0.115$ & 16 & $4.683 \pm 0.065$ & 16 \\
Brain, \% Body weight & ${ }^{* *} 0.86 \pm 0.027$ & 12 & $0.685 \pm 0.010$ & 12 \\
Hematocrit, \% & ${ }^{* *} 16.04 \pm 0.72$ & 16 & $43.02 \pm 0.47$ & 16 \\
Serum iron, mg/ml & ${ }^{*} 0.61 \pm 0.06$ & 16 & $2.183 \pm 0.11$ & 16 \\
Liver iron, mg/g & ${ }^{* *} 14.84 \pm 0.78$ & 16 & $62.17 \pm 3.69$ & 16 \\
\hline
\end{tabular}

Values are means \pm SEM. ${ }^{* *} \mathrm{P}<0.001,{ }^{*} \mathrm{P}<0.05$ compared with control rats, ANOVA.

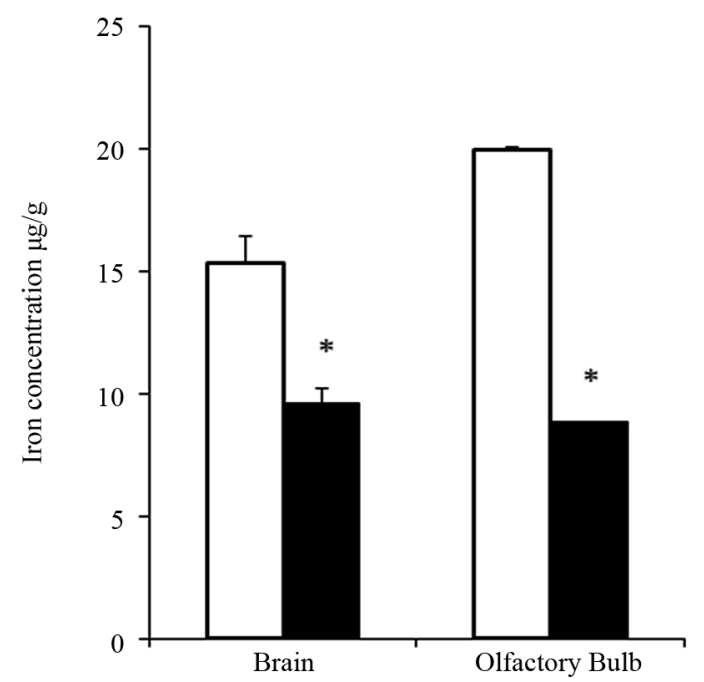

Figure 1. ICP-OES analysis of iron in olfactory bulbs and whole brains of iron-deficient and control rats. Iron content was measured in olfactory bulb $(n=8)$ and whole brain $(n=$ 10) of iron-deficient (black bars) and control (white bar) rats. Results shown are mean values \pm SEM. ${ }^{*} p<0.001$, ANOVA. 


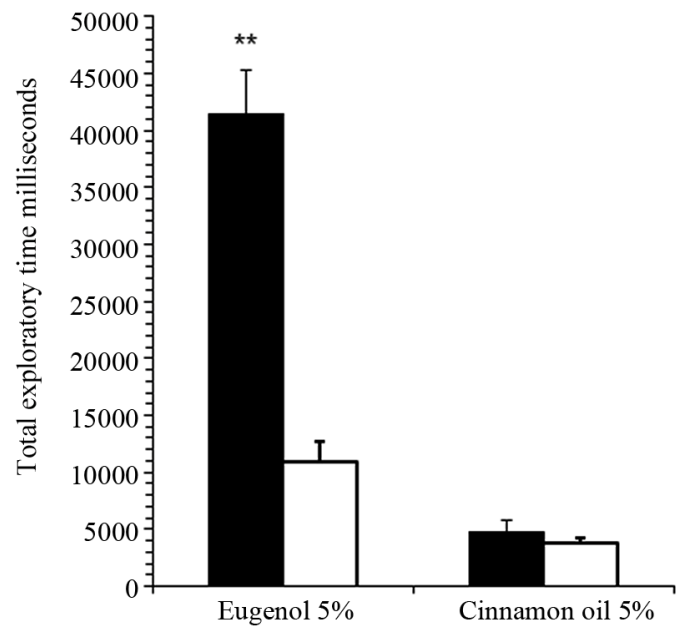

(a)

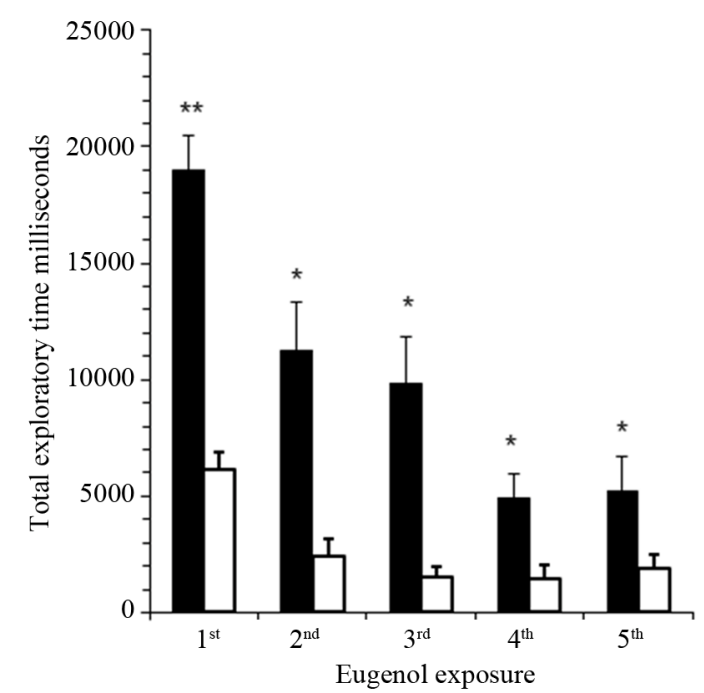

(b)

Figure 2. Iron-deficient rats show significantly prolonged sniffing time in behavioral olfactory habituation/dis-habituation test. Panel (a): Total exploratory time within five trial sessions of 180 seconds each was determined for anemic rats (black bars) compared with control rats (white bars) for the attractive odorant $5 \%$ eugenol and the aversive odorant, cinnamon oil. The graph shows mean total sniffing times \pm SEM (n = 16). "P < 0.001, ANOVA; Panel (b): Exploratory time for attractive odorant $5 \%$ eugenol is shown for each individual trial session of 180 seconds. ${ }^{* *} \mathrm{P}<0.001$, ${ }^{*} \mathrm{P}<0.05$, ANOVA.

\subsection{Olfactory Preference Test}

Total exploratory time within 180 seconds compared preference for a second set of attractive and aversive odorants (Figure 3). Iron-deficient rats had significantly prolonged exploration of the attractive odorant peanut butter compared with control rats $(\mathrm{P}<0.001$; $\mathrm{n}=10$ ). There was no significant difference in total exploratory time for the aversive odorant 2-methylbutyric acid comparing anemic rats and control rats.

\subsection{Olfactory Sensitivity Test with Attractive Odorants Eugenol and Peanut Butter}

There were significantly prolonged exploratory times within 180 second for increased dose of attractive odorant, with $1.8 \%$ eugenol $(\mathrm{P}<0.05, \mathrm{n}=5)$ and $3.6 \%$ eugenol $(\mathrm{P}$ $<0.005, \mathrm{n}=6$ ) in anemic rats compared with control rats (Figure 4). Similar observations were made for a second odor, $5 \%$ peanut butter $(\mathrm{P}<0.05, \mathrm{n}=5$ ) and $10 \%$ peanut butter $(P<0.005, n=6$ ) (Figure 5). Olfactory sensitivity for iron-deficient rats appeared dose-dependent for both attractants, unlike the control group of iron-sufficient rats.

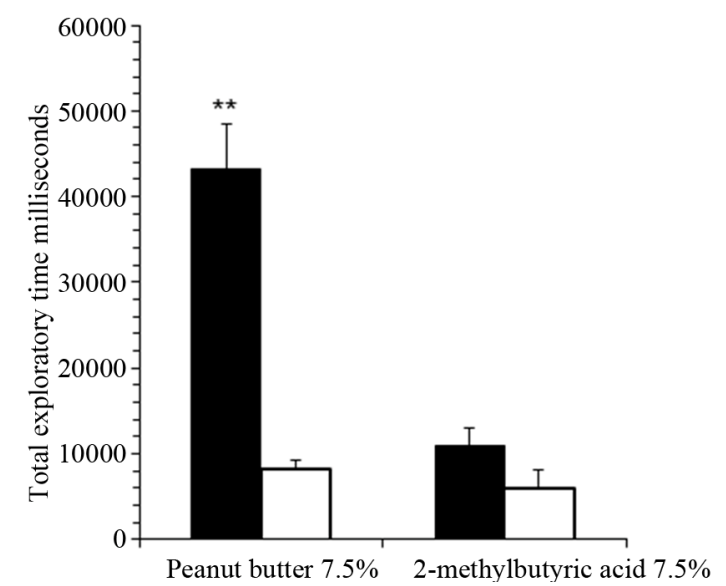

Figure 3. Iron-deficient rats showed significantly prolonged sniffing time for attractive but not aversive odorants in behavioral olfactory preference test. Total exploratory time for $7.5 \%$ peanut butter and $7.5 \%$ 2-methylbutric acid in iron-deficient rats (black bars) compared with control rats (white bars). The graph shows mean total sniffing times \pm $\operatorname{SEM}(\mathrm{n}=10) .{ }^{* *} \mathrm{P}<0.001$, ANOVA.

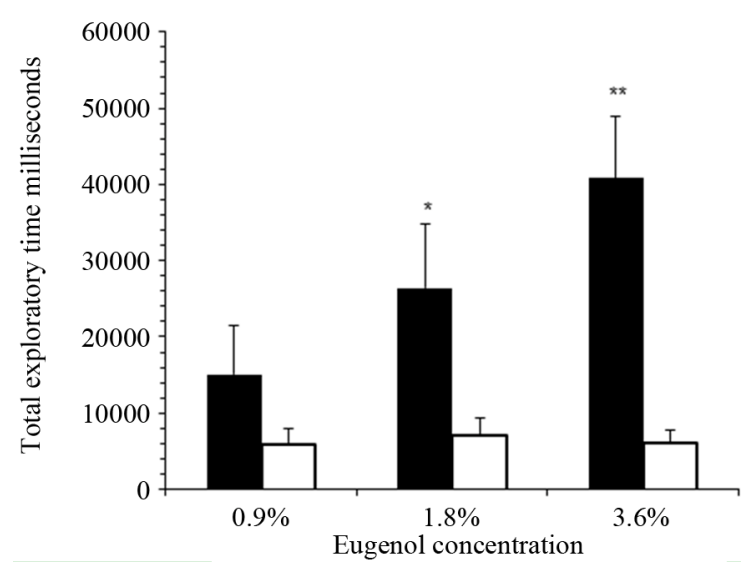

Figure 4. Iron-deficient rats showed significantly pro-longed sniffing time for attractive odorants in behavioral olfactory sensitivity tests in dose-dependent manner. Total exploratory time for $0.9 \%(n=5), 1.8 \%(n=5)$ and $3.6 \%$ eugenol $(n=6)$ were determined for iron-deficient rats (black bars) compared with control rats (white bars). The graph shows mean total sniffing times \pm SEM. ${ }^{* * *} \mathbf{P}<\mathbf{0 . 0 0 5},{ }^{*} \mathbf{P}<\mathbf{0 . 0 5}$, ANOVA. 


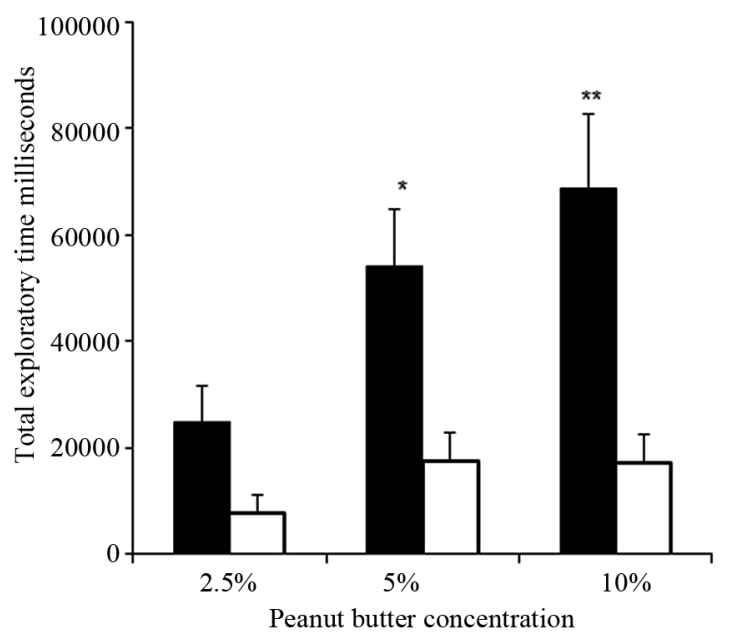

Figure 5. Iron-deficient rats showed significantly prolonged sniffing time for peanut butter in behavioral olfactory sensitivity tests in dose-dependent manner. Total exploratory time for $2.5 \%(n=5), 5 \%(n=5)$ and $10 \%$ peanut butter $(n$ $=6$ ) in iron-deficient rats (black bars) compared with control rats (white bars). The graph shows mean total sniffing times \pm SEM. ${ }^{* *} \mathrm{P}<0.005,{ }^{*} \mathrm{P}<0.05$, ANOVA.

\section{Discussion}

The main aim of the present study was to determine whether iron deficiency could affect the behavioral olfactory function. Iron-deficiency anemia was induced by feeding weanling rats a low iron diet (4 - $7 \mathrm{ppm})$, and olfactory behavior was compared to age-matched rats fed an isocaloric diet with standard chow iron concentration (210 - 220 ppm). Significantly lower hematocrit values, serum iron, and non-heme iron in the liver established low body iron status for the iron-deficient group compared to the iron-sufficient group. Notably, the iron content of brain and olfactory bulbs were significantly reduced in the anemic cohort compared to the control rats, $62.8 \%$ and $44.4 \%$ respectively.

According to previously published research on behaveioral olfactory function, animals detect and discriminate odors through brief bouts of high frequency sniffing, which plays an important role in odor information processing [18-22]. Sniffing or exploratory time is therefore a reliable indicator of olfactory function [25-28]. In our study, we used both attractive and aversive odorants since these are associated with different mechanisms of action in detection and discrimination. General detection and discrimination of odors occur against an odorous background. On any given inhalation, olfactory receptor neurons will be activated by features of both the target odorant and features of background stimuli. We used vanillin (200 $\mathrm{mg} / \mathrm{vial} / \mathrm{cage}$ ) for enrichment and as a background odorant to habituate rats continuously for 7 days; the vanillin odorant was completely ignored by all rats after 5 - 7 days. In the olfactory habituation/dis-habituation tests, iron-defi- cient rats showed significantly prolonged exploratory time to an attractant order (eugenol) compared to iron-sufficient controls.

Both groups detected and discriminated an aversive odorant (cinnamon oil) very quickly after dis-habituation. The olfactory preference tests for anemic rats also showed significantly prolonged exploratory time for $7.5 \%$ peanut butter while no significant difference was observed for a second aversive odorant, 7.5\% 2-methylbutyric acid, compared with control rats.

One plausible explanation accounting for the observed behavioral differences between the two groups is that iron deficiency reduces self and lateral inhibition (see Figure 6). This reasoning is based on the idea that aversive odorant signaling is independent of N-methyl-D-aspartc acid (NMDA) receptors as well as pathways that involve nitric oxide (NO), glutamate, $\gamma$-aminobutryic acid (GABA); serotonergic signaling appears to be involved

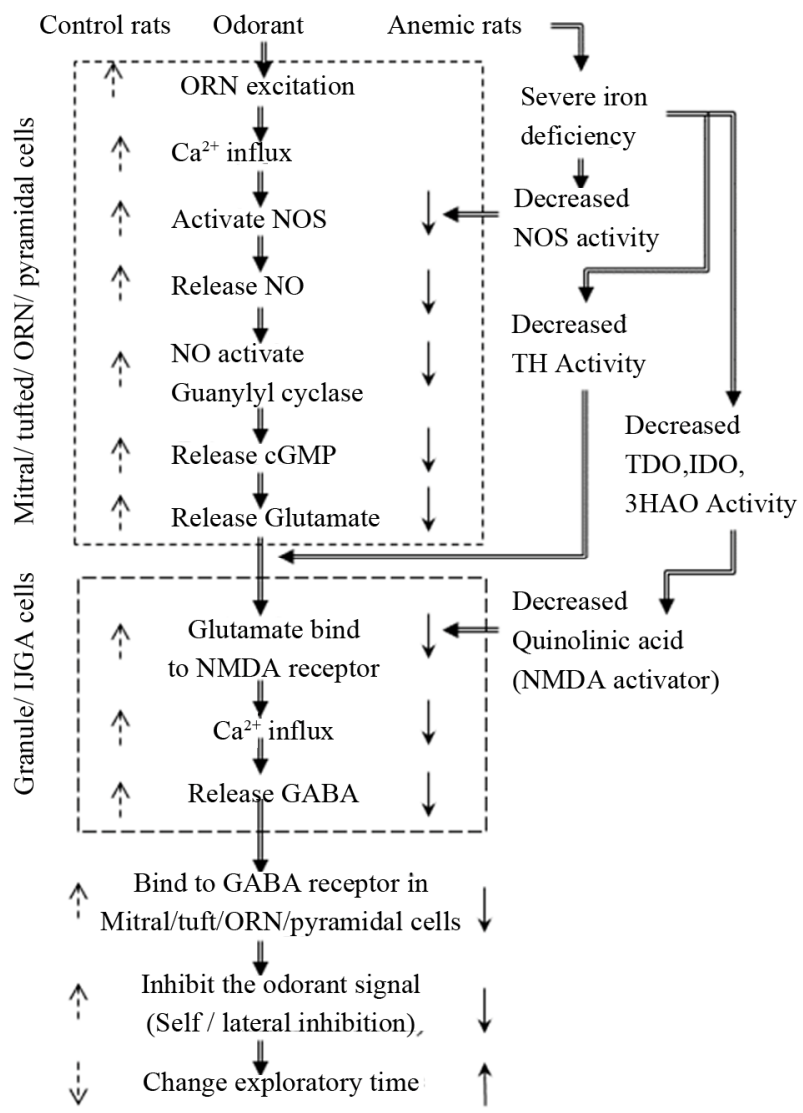

Figure 6. Iron involvement and mechanism of action in behavioral olfactory functions in anemic rats. In iron deficiency anemia, enzymatic activities of NOS, TDO, IDO, 3-HAO and TH enzymes are reduced due to lack of heme or iron as co-factors. These deficiencies, in turn, reduce self/lateral inhibition, which increases exploratory time in behavioral olfactory habituation/dis-habituation, preference and sensitivity tests. $\downarrow$ indicates reduced activity, $\uparrow$ indicates increased activity. 
instead [29-32]. Chaudhury et al. have shown that mitral cells adapt to repeated odorant stimulation with 5-min inter-trial intervals in a time course experiment similar to that of the behavioral habituation [26]. The histogram patterns of exploratory time we observed are also comparable to geraniol-evoked electro-olfactogram recordings of olfactory sensory nerve cells that are subject to nitric oxide synthase (NOS) inhibition or that are deficient in eNOS [33]. Iron could be involved in at least three important functions controlling self and lateral inhibition inputs. Heme is a cofactor for NOS activity, which mediates exchange of GABA and glutamate through NMDA receptors. NO is directly involved in glutamate release from olfactory receptor neurons (ORN), mitral and/or tufted cells which in turn release GABA to exhibit self and lateral inhibition necessary for olfactory behavior and learning in animals [34-38]. Iron is also required as a co-factor for TDO, IDO, and 3-HAO. These enzymes function in the kynurenine pathway, which is involved in the synthesis of quinolinic acid known to activate NMDA receptors in mitral and granule cells [39-43]. In the third mechanism, iron is required as a co-factor for TH, a key enzyme in the synthesis of dopamine in dopaminergic-GABAergic juxtaglomerular neurons (DA neurons) which modulate the release of glutamate from olfactory receptor neurons that are involved in presynaptic inhibition of odorant signal [44-48].

Our findings are further supported by recent studies by Cheranova et al. $[49,50]$. These investigators suggest that heme is necessary for the regulation of NMDA receptors. Their observations are interesting because Mandarion et al. [51,52] have suggested that NMDA-dependent plasticity is involved in the changes in olfactory processing and local blockade of NMDA receptors blocks the effects of daily odor enrichment. This simple mechanism may explain the rather dramatic differences observed for anemic rats and attractive odorants compared to controls, especially since local heme levels could be anticipated to be significantly lower based on the reduced iron content in olfactory bulbs shown in Figure 1.

Biochemical mechanism and consequences behind these olfactory functions are illustrated in Figure 6 and are explained as follows. Upon exposure to odorant, the olfactory sensory neuron generates an action potential that is transduced to mitral cell dendrites in the olfactory glomerulus. Voltage-gated calcium channels open in mitral cell dendrites, and this calcium influx causes activation of NOS to release NO, which in turn activates soluble guanylyl cyclase to produce cGMP. Guanylyl cyclase is not expressed in granule or IJGA (GABAergic cells) cells therefore NO generated in these cells must diffuse to mitral/ tufted cells or the ORN cell to activate guanylyl cyclase and produce cGMP. Cyclic GMP causes exocytosis of glutamate from mitral cell dendrites that binds to and opens NMDA and AMPA receptors on granule cell spines. This causes depolarization which results in calcium influx through voltage-gated calcium channels. Calcium elevation in these spines results in $\gamma$-aminobutyric acid (GABA) release to activate GABA receptors on mitral cell dendrites, inhibiting the odor-generated action potentials. Interestingly, soluble guanylyl cyclase is present in mitral/tufted cells that produce cGMP and release glutamate to granule/IJGA cells whereas glutamic acid decarboxylase, which produces GABA from glutamate, is found almost exclusively in GABAergic neurons such as granule/IJGA cells (Figure 6). These cellular arrangements and synaptic mechanisms mediate the coupling between mitral/tufted and granule/IJGA cells, and support the function of inhibitory olfactory bulb circuits [53-57].

\section{Conclusion}

The present investigation suggests that iron-deficiency alters olfactory behavior. Iron is a co-factor for NOS, TDO, IDO, 3-HAO and TH enzyme activities, which control behavioral olfactory functions by participating in signaling through self and lateral inhibition. Because iron deficiency would decrease these enzyme activities, we speculate this condition promotes reduced self and lateral inhibition. Thus, the odorant signal remains strong for longer time, prolonging exploratory time when compared with iron-sufficient control rats. Future experiments are necessary to test this hypothesis, and to further understand the role of iron in olfaction

\section{REFERENCES}

[1] M. B. Antunes, R. Bowler and R. L. Doty, "San Francisco/Oakland Bay Bridge Welder Study: Olfactory Function,” Neurology, Vol. 69, No. 12, 2007, pp. 1278-1284. doi:10.1212/01.wnl.0000276988.50742.5e

[2] R. L. Doty, M. Riklan, D. A. Deems, C. Reynolds and S. Stellar, "The Olfactory and Cognitive Deficits of Parkinson's Disease: Evidence for Independence," Annals of Neurology, Vol. 25, No. 2, 1989, pp. 166-171. doi:10.1002/ana.410250210

[3] T. Baba, A. Takeda, A. Kikuchi, Y. Nishio, Y. Hosokai, K. Hirayama, T. Hasegawa, N. Sugeno, K. Suzuki, E. Mori, S. Takahashi, H. Fukuda and Y. Itoyama, "Association of Olfactory Dysfunction and Brain. Metabolism in Parkinson's Disease," Movement Disorders, Vol. 26, No. 4, 2011, pp. 621-628. doi: 10.1002/mds.23602

[4] M. Fusetti, A. B. Fioretti, F. Silvagni, M. Simaskou, P. Sucapane, S. Necozione and A. Eibenstein, "Smell and Preclinical Alzheimer Disease: Study of 29 Patients with Amnesic Mild Cognitive Impairment," Journal of Otolaryngology Head and Neck Surgery, Vol. 39, No. 2, 2010, pp. 175-181. doi:10.2310/7070.2009.090046

[5] S. Forster, A. Vaitl, S. J. Teipel, I. Yakushev, M. Mustafa, C. la Fougere, A. Rominger, P. Cumming, P. Bartenstein, H. Hampel, T. Hummel, K. Buerger, W. Hundt and S. 
Steinbach, "Functional Representation of Olfactory Impairment in Early Alzheimer's Disease,” Journal of Alzheimers Disease, Vol. 22, No. 2, 2010, pp. 581-591. doi:10.3233/JAD-2010-091549

[6] T. Kovacs, "Mechanisms of Olfactory Dysfunction in Aging and Neurodegenerative Disorders," Ageing Research Reviews, Vol. 3, No. 2, 2004, pp. 215-232. doi:10.1016/j.arr.2003.10.003

[7] H. J. Westervelt, J. Carvalho and K. Duff, "Presentation of Alzheimer's Disease in Patients with and without Olfactory Deficits," Archives of Clinical Neuropsychology, Vol. 22, No.1, 2007, pp. 117-122. doi:10.1016/j.acn.2006.11.005

[8] J. F. Morley and J. E. Duda, "Olfaction as a Biomarker in Parkinson’s Disease,” Biomark Medicine, Vol. 4, No. 5, 2010, pp. 661-670. doi:10.2217/BMM.10.95

[9] R. I. Mesholam, P. J. Moberg, R. N. Mahr and R. L. Doty, "Olfaction in Neurodegenerative Disease: A Meta-Analysis of Olfactory Functioning in Alzheimer's and Parkinson's diseases," Archives of Neurology, Vol. 55, No. 1, 1998, pp. 84-90. doi:10.1001/archneur.55.1.84

[10] M. W. Albers, M. H. Tabert and D. P. Devanand, “Olfactory Dysfunction as a Predictor of Neurodegenerative Disease," Current Neurology and Neuroscience Reports, Vol. 6, No. 5, 2006, pp. 379-386. doi:10.1007/s11910-996-0018-7

[11] R. L. Doty, "The Olfactory Vector Hypothesis of Neurodegenerative Disease: Is It Viable?” Annals of Neurology, Vol. 63, No. 1, 2008, pp. 7-15. doi:10.1002/ana.21327

[12] J. Wang, P. J. Eslinger, R. L. Doty, E. K. Zimmerman, R. Grunfeld, X. Sun, M. D. Meadowcroft, J. R. Connor, J. L. Price, M. B. Smith and Q. X. Yang, "Olfactory Deficit Detected by fMRI in Early Alzheimer's Disease,” Brain Research, Vol. 1357, 2010, pp. 184-194. doi:10.1016/j.brainres.2010.08.018

[13] M. Schrag, C. Mueller, U. Oyoyo, M. A. Smith and W. M. Kirsch, "Iron Zinc and Copper in the Alzheimer's Disease Brain: A Quantitative Meta-Analysis. Some Insight on the Influence of Citation Bias on Scientific Opinion," Progress in Neurobiology, Vol. 94, No. 3, 2011, pp. 296306. doi:10.1016/j.pneurobio.2011.05.001

[14] G. A. Salvador, R. M. Uranga and N. M. Giusto, "Iron and Mechanisms of Neurotoxicity," International Journal of Alzheimers Disease, Vol. 2011, 2010, Article ID 720658. doi: 10.4061/2011/720658

[15] W. Y. Ong and A. A. Farooqui, "Iron, Neuroinflammation, and Alzheimer's Disease," Journal of Alzheimers Disease, Vol. 8, No. 2, 2005, pp. 183-200, discussion pp. 209-115.

[16] C. Quintana, S. Bellefqih, J. Y. Laval, J. L. GuerquinKern, T. D. Wu, J. Avila, I. Ferrer, R. Arranz and C. Patino, "Study of the Localization of Iron, Ferritin, and Hemosiderin in Alzheimer's Disease Hippocampus by Analytical Microscopy at the Subcellular Level,” Journal of Structural Biology, Vol. 153, No. 1, 2006, pp. 42-54. doi:10.1016/j.jsb.2005.11.001

[17] T. A. Rouault, "Systemic Iron Metabolism: A Review and Implications for Brain Iron Metabolism,” Pediatric Neu- rology, Vol. 25, No. 2, 2001, pp. 130-137. doi:10.1016/S0887-8994(01)00260-0

[18] B. N. Johnson, J. D. Mainland and N. Sobel, "Rapid Olfactory Processing Implicates Subcortical Control of an Olfactomotor System,” Journal of Neurophysiology, Vol. 90, No. 2, 2003, pp. 1084-1094. doi:10.1152/jn.00115.2003

[19] J. Porter, B. Craven, R. M. Khan, S. J. Chang, I. Kang, B. Judkewitz, J. Volpe, G. Settles and N. Sobel, "Mechanisms of Scent-Tracking in Humans," Nature Neuroscience, Vol. 10, No. 1, 2007, pp. 27-29. doi:10.1038/nn0207-263d

[20] S. L. Youngentob, M. M. Mozell, P. R. Sheehe and D. E. Hornung, "A Quantitative Analysis of Sniffing Strategies in Rats Performing Odor Detection Tasks,” Physiology \& Behavior, Vol. 41, No. 1, 1987, pp. 59-69. doi:10.1016/0031-9384(87)90131-4

[21] K. G. Sorwell, D. W. Wesson and M. J. Baum, "Sexually Dimorphic Enhancement by Estradiol of Male Urinary Odor Detection Thresholds in Mice," Behavioral Neuroscience, Vol. 122, No. 4, 2008, pp. 788-793. doi:10.1037/0735-7044.122.4.788

[22] D. W. Wesson, T. N. Donahou, M. O. Johnson and M. Wachowiak, "Sniffing Behavior of Mice during Performance in Odor-Guided Tasks," Chemical Senses, Vol. 33, No. 7, 2008, pp. 581-596. doi:10.1093/chemse/bjn029

[23] M. Yang and J. N. Crawley, "Simple Behavioral Assessment of Mouse Olfaction," Current Protocols in Neuroscience, Chapter 8, 2009, Unit 8.24. doi:10.1002/0471142301.ns0824s48

[24] J. D. Brain, E. Heilig, T. C. Donaghey, M. D. Knutson, M. Wessling-Resnick and R. M. Molina, "Effects of Iron Status on Transpulmonary Transport and Tissue Distribution of $\mathrm{Mn}$ and Fe," American Journal of Respiratory Cell and Molecular Biology, Vol. 34, No. 3, 2006, pp. 330-337. doi:10.1165/rcmb.2005-01010C

[25] M. Kadohisa and D. A. Wilson, "Olfactory Cortical Adaptation Facilitates Detection of Odors against Background," Journal of Neurophysiology, Vol. 95, No. 3, 2006, pp. 1888-1896. doi:10.1152/jn.00812.2005

[26] D. Chaudhury, L. Manella, A. Arellanos, O. Escanilla, T. A. Cleland and C. Linster, "Olfactory Bulb Habituation to Odor Stimuli,” Behavioral Neuroscience, Vol. 124, No. 4, 2010, pp. 490-499. doi:10.1037/a0020293

[27] K. Kobayakawa, R. Kobayakawa, H. Matsumoto, Y. Oka, T. Imai, M. Ikawa, M. Okabe, T. Ikeda, S. Itohara, T. Kikusui, K. Mori and H. Sakano, "Innate versus Learned Odour Processing in the Mouse Olfactory Bulb,” Nature, Vol. 450, No. 7169, 2007, pp. 503-508. doi:10.1038/nature06281

[28] R. M. Witt, M. M. Galligan, J. R. Despinoy and R. Segal, "Olfactory Behavioral Testing in the Adult Mouse," Journal of Visualized Experiment, Vol. 23, 2009, p. 949. doi:10.3791/949

[29] T. Yabumoto, F. Takanashi, Y. Kirino and S. Watanabe, "Nitric Oxide Is Involved in Appetitive but Not Aversive Olfactory Learning in the Land Mollusk Limax Valentianus," Learning \& Memory, Vol. 15, No. 4, 2008, pp. 
229-232. doi:10.1101/lm.936508

[30] A. C. Keene and S. Waddell, "Drosophila Memory: Dopamine Signals Punishment?” Current Biology, Vol. 15, No. 22, 2005, pp. R932-R934. doi:10.1016/j.cub.2005.11.040

[31] S. Unoki, Y. Matsumoto and M. Mizunami, "Participation of Octopaminergic Reward System and Dopaminergic Punishment System in Insect Olfactory Learning Revealed by Pharmacological Study," European Journal of Neuroscience, Vol. 22, No. 6, 2005, pp. 1409-1416. doi:10.1111/j.1460-9568.2005.04318.x

[32] V. Vergoz, E. Roussel, J. C. Sandoz and M. Giurfa, "Aversive Learning in Honeybees Revealed by the Olfactory Conditioning of the Sting Extension Reflex," PLoS One, Vol. 2, No. 23, 2007, p. e288. doi:10.1371/journal.pone.0000288

[33] D. Brunert, S. Kurtenbach, S. Isik, H. Benecke, G. Gisselmann, W. Schuhmann, H. Hatt and C. H. Wetzel, "Odorant-Dependent Generation of Nitric Oxide in Mammalian Olfactory Sensory Neurons,” PLoS One, Vol. 4, No. 5, 2009, p. e5499. doi:10.1371/journal.pone.0005499

[34] M. Doengi, D. Hirnet, P. Coulon, H.C. Pape, J.W. Deitmer and C. Lohr, "GABA Uptake-Dependent $\mathrm{Ca}(2+)$ Signaling in Developing Olfactory Bulb Astrocytes," Proceedings of the National Academy of Sciences USA, Vol. 106, No. 41, 2009, pp. 17570-17575. doi:10.1073/pnas.0809513106

[35] A. Larkin, S. Karak, R. Priya, A. Das, C. Ayyub, K. Ito, V. Rodrigues and M. Ramaswami, "Central Synaptic Mechanisms Underlie Short-Term Olfactory Habituation in Drosophila Larvae," Learning \& Memory, Vol. 17, No. 12, 2010, pp. 645-653. doi:10.1101/lm.1839010

[36] S. Das, M. K. Sadanandappa, A. Dervan, A. Larkin, J. A. Lee, I. P. Sudhakaran, R. Priya, R. Heidari, E. E. Holohan, A. Pimentel, A. Gandhi, K. Ito, S. Sanyal, J. W. Wang, V. Rodrigues and M. Ramaswami, "Plasticity of Local Gabaergic Interneurons Drives Olfactory Habituation,” Proceedings of the National Academy of Sciences USA, Vol. 108, No. 36, 2011, pp, E646-654. doi:10.1073/pnas.1106411108

[37] R. Matsuo and E. Ito, “A Novel Nitric Oxide Synthase Expressed Specifically in the Olfactory Center," Biochemical and Biophysical Research Communications, Vol. 386, No. 4, 2009, pp. 724-728. doi:10.1016/j.bbrc.2009.06.112

[38] B. Samama and N. Boehm, "Inhibition of Nitric Oxide Synthase Impairs Early Olfactory Associative Learning in Newborn Rats,” Neurobiology of Learn Memory, Vol. 71, No. 2, 1999, pp. 219-231. doi:10.1006/nlme.1998.3869

[39] M. R. Poston, M. S. Bailey, R. Schwarcz and M. T. Shipley, "Differential Complementary Localization of Metabolic Enzymes for Quinolinic Acid in Olfactory Bulb Astrocytes," The Journal of Comparative Neurology, Vol. 311, No. 3, 1991, pp. 367-374. doi:10.1002/cne.903110307

[40] J. C. Brown III, H. W. Tse, D. A. Skifter, J. M. Christie, V. J. Andaloro, M. C. Kemp, J. C. Watkins, D. E. Jane and D. T. Monaghan, "[3H]Homoquinolinate Binds to a Subpopulation of NMDA Receptors and to a Novel
Binding Site,” Journal of Neurochemistry, Vol. 71, No. 4, 1998, pp. 1464-1470. doi:10.1046/j.1471-4159.1998.71041464.x

[41] M. Wolfensberger, U. Amsler, M. Cuenod, A.C. Foster, W. O. Whetsell Jr. and R. Schwarcz, "Identification of Quinolinic Acid in Rat and Human Brain Tissue," Neuroscience Letters, Vol. 41, No. 3, 1983, pp. 247-252. doi:10.1016/0304-3940(83)90458-5

[42] T. W. Stone, "Neuropharmacology of Quinolinic and Kynurenic Acids,” Pharmacological Reviews, Vol. 45, No. 3, 1993, pp. 309-379.

[43] G. J. Guillemin, K. M. Cullen, C. K. Lim, G. A. Smythe, B. Garner, V. Kapoor, O. Takikawa and B. J. Brew, "Characterization of the Kynurenine Pathway in Human Neurons,” Journal of Neuroscience, Vol. 27, No. 47, 2007, pp. 12884-12892. doi:10.1523/JNEUROSCI.4101-07.2007

[44] G. G. Collins, J. Anson and G. A. Probett, "Excitatory and Inhibitory Effects of Dopamine on Synaptic Transmission in the Rat Olfactory Cortex Slice," Brain Research, Vol. 333, No. 2, 1985, pp. 237-245. doi:10.1016/0006-8993(85)91577-X

[45] J. W. Cave and H. Baker, "Dopamine Systems in the Forebrain," Advances in Experimental Medicine and Biology, Vol. 651, 2009, pp. 15-35. doi:10.1007/978-1-4419-0322-8 2

[46] M. Ennis, F. M. Zhou and K. J. Ciombor, "Dopamine D2 Receptor-Mediated Presynaptic Inhibition Olfactory Nerve Terminals," Journal of Neurophysiology, Vol. 86, No. 6 , 2001, pp. 2986-2997.

[47] D. A. Berkowicz and P. Q. Trombley, "Dopaminergic Modulation at the Olfactory Nerve Synapse,” Brain Research, Vol. 855, No. 1, 2000, pp. 90-99. doi:10.1016/S0006-8993(99)02342-2

[48] A. Y. Hsia, J. D. Vincent and P. M. Lledo. "Dopamine Depresses Synaptic Inputs into the Olfactory Bulb,” Journal of Neurophysiology, Vol. 82, No. 2, 1999, pp. 1082 1085.

[49] T. Chernova, J. R. Steinert, P. Richards, R. Mistry, R. A. Challiss, R. Jukes-Jones, K. Cain, A. G. Smith and I. D. Forsythe, "Early Failure of N-Methyl-D-Aspartate Receptors and Deficient Spine Formation Induced by Reduction of Regulatory Heme in Neurons," Molecular Pharmacology, Vol. 79, No. 5, 2011, pp. 844-854. doi:10.1124/mol.110.069831

[50] T. Chernova, P. Nicotera and A. G. Smith, "Heme deficiency Is Associated with Senescence and Causes Suppression of N-Methyl-D-Aspartate Receptor Subunits Expression in Primary Cortical Neurons," Molecular Pharmacology, Vol. 69, No. 3, 2006, pp. 697-705. doi:10.1124/mol.105.016675

[51] N. Mandairon, C. Stack, C. Kiselycznyk and C. Linster, "Broad Activation of the Olfactory Bulb Produces LongLasting Changes in Perception," Proceedings of the $\mathrm{Na}$ tional Academy of Sciences, Vol. 103, No. 36, 2006, pp. 13543-13548. doi:10.1073/pnas.0602750103

[52] N. Mandairon, C. Stack and C. Linster, "Olfactory Enrichment Improves the Recognition of Individual Components in Mixtures,” Physiology \& Behavior, Vol. 89, 
No. 3, 2006, pp. 379-384.

doi:10.1016/j.physbeh.2006.07.013

[53] N. N. Urban and B. Sakmann, "Reciprocal Intraglomerular Excitation and Intra- and Interglomerular Lateral Inhibition between Mouse Olfactory Bulb Mitral Cells,” Journal of Physiology, Vol. 542, No. 2, 2002, pp. 355-367. doi:10.1113/jphysiol.2001.013491

[54] K. Mori and S. F. Takagi, “An Intracellular Study of Dendrodendritic Inhibitory Synapses on Mitral Cells in the Rabbit Olfactory Bulb,” Journal of Physiology, Vol. 279, 1978, pp. 569-588.

[55] C. E. Jahr and R. A. Nicoll, "Dendrodendritic Inhibition:
Demonstration with Intracellular Recording," Science, Vol. 207, No. 4438, 1980, pp. 1473-1475. doi:10.1126/science.7361098

[56] M. C. Nowycky, K. Mori and G. M. Shepherd, “GABAergic Mechanisms of Dendrodendritic Synapses in Isolated Turtle Olfactory Bulb,” Journal of Neurophysiology, Vol. 46, No. 3, 1981, pp. 639-648.

[57] J. S. Isaacson and B. W. Strowbridge, "Olfactory Reciprocal Synapses: Dendritic Signaling in the CNS,” Neuron, Vol. 20, No. 4, 1998, pp. 749-761. doi:10.1016/S0896-6273(00)81013-2 